\title{
Using Worldview-2 Satellite Imagery to Support Geoscience Studies on Phlegraean Area
}

\author{
Pasquale Maglione, Claudio Parente and Andrea Vallario \\ Department of Applied Sciences, \\ Faculty of Sciences and Technologies, University of Naples "Parthenope", Naples, Italy
}

Received 2013-07-09, Revised 2013-07-11; Accepted 2013-07-24

\begin{abstract}
WorldView-2 satellite imagery includes half-meter panchromatic resolution and $2 \mathrm{~m}$ multispectral resolution. Because of the reduced dimensions of pixels and articulated spectral acquisition these images supply detailed information that can be used for geoscience applications, above all to investigate areas, identify land cover, bound vegetated zones, outline transformations (change detection). The aim of this study is to remark possibilities to use WorldView-2 imagery for analysis of Phlegrean area (Italy), facilitating monitoring actions and increasing level of knowledge of territorial and environmental features. This area is emblematic for many aspects such as its geological history, the presence of volcanic activities, the Roman ruins and the natural forest. The study is centered on methodological aspects about the use of WorldView-2 imagery for increasing dataset and level of information. For consequence attention is firstly focalized on possibilities to obtain geometrical corrected data with adequate accuracy (comparable to pixel dimensions): using Rational Polynomial Functions for ortho-rectification, references are already georeferred air-photos with cell-size equal to that of WorldView-2 higher resolution images (panchromatic band: $0.50 \times 0.50 \mathrm{~m}$ ), while Digital Terrain Model (DTM) is built with cartographic dataset in scale 1: 5,000. Then other two methodological aspects on WorlView-2 imagery use are considered: Normalized Difference Vegetation Index (NDVI) application and 3d photo-realistic model construction. In the first case thresholds determination to distinguish vegetated areas is conducted using Maximum Likelihood method based on training sites to achieve high level of thematic accuracy; in the second RGB composition is obtained and overlapped to DTM.
\end{abstract}

Keywords: WorldView-2 Satellite Imagery, Rational Polynomial Functions, Phlegrean Area, NDVI, 3D Models

\section{INTRODUCTION}

Remote sensing by satellite supplies datasetson the earth observations that are fundamental to efficiently manage renewable resources and use judiciously nonrenewable ones.

At first civilian space remote sensing consisted of experimental missions to develop proofs of concepts for any applications that had a sound scientific basis and some, perhaps, that did not. All of the missions conducted in the 1960s and 1970s, including Gemini, Apollo, Skylab, Apollo-Soyuz and the early Landsat, were approved and funded as experiments to advance space science (Morain and Budge, 2012).
Successively other motivations supported remote sensing programs such as the need for better information about the earth's features. In fact to wisely plan human activities and rationally use earth resources, acquisition and analysis of data concerning environmental and territorial structures are necessary.

In the late 1960 earth-orbit satellite appeared as the best means to acquire the needed data so to obtain continuous and nearly synoptic coverage of terrestrial resources for understanding and measuring earth system processes at regional, continental, or global scale (Lauer et al., 1997).

The fundament of remote sensing is that different materials reflect and absorb differently at different wavelength. Plotting the fraction of radiation reflected as

Corresponding Author: Pasquale Maglione, Department of Applied Sciences, Faculty of Sciences and Technologies, University of Naples "Parthenope", Naples, Italy 
a function of the incident wavelength, a unique signature is obtained for each material. In this way earth features can be distinguished on the basis of their spectral reflectance (Simonett and Ulaby, 1983).

Although remote sensing involves the measurement of energy in many parts of the electromagnetic spectrum, the major region of interest are visible light, reflected and emitted infrared and passive and active microwave frequencies (Lein, 2012). Since 1970s multispectral sensors were assembled to detect radiations from an object distinguishing them in reference to different electromagnetic regions (spectral bands) (Gibson, 2000), so to obtain several images for applications in many fields (agriculture, mineralogy, physics, forestry and so on). Firstly scanners with tens of channels were assembled for aircraft research; experiments conducted under controlled laboratory conditions permitted to collect spectral signatures of several different materials. Image processing advancement was remarked by development of several algorithms to derived information, just think of Vegetation Indexes for identifying vegetated areas, such as Normalized Difference Vegetation Index (NDVI) (Rouse et al., 1974), Tasseled Cap transformations (Kauth and Thomas, 1976), SoilAdjusted Vegetation Index (SAVI) (Huete, 1988).

Sensors on board satellite, such as Landsat-1 Multispectral Scanner System (MSS) were designed to provide observations of the earth to distinguish land/water interface, vegetated/non vegetated areas, forested/non forested lands, urban/non-urban areas, agricultural/non-agricultural lands. Each of these categories is very important for formulating upwardspiraling interpretation of human economic uses of the land, for assessing environmental health and for addressing what would later be called earth system science (Morain and Budge, 2012).

By virtue of their orbital repeat cycle (14-18 days) satellites offer scientists opportunity to observe surface covers at regular and short intervals. For consequence remote sensing becomes fundamental for monitoring of earth resources and environmental conditions: for example, observing the annual greening and yellowing cycles of vegetation, variability of spectral responses through time are used for the assessment of biomass production and condition (Campbell and Wynne, 2011).

High quality data are routinely acquired and used to better measure and monitor earth resources. The early sensors supplied images with pixel dimensions of some tens meters (for example: Landsat TM, $30 \times 30 \mathrm{~m}$ ); geometric resolution has been increasing over time. The successful launch of the first Very High Resolution (VHR) satellite, such as IKONOS in September 1999 or
Quickbird in October 2001, marked the beginning of a wholly new age in remote sensing; in fact, VHR satellite are able to capture images of the earth's surface with a Ground Sample Distance (GSD) of $1 \mathrm{~m}$ and even less (Aguilar et al., 2013). IKONOS satellite images (pan: $1 \times 1 \mathrm{~m}$, multispectral $4 \times 4 \mathrm{~m}$ ) are used for many applications such as to establish accurately variation of shorelines in presence of coastal erosion (Basile et al., 2011). Recently cell size of 50 centimeters have been achieved for panchromatic data, such as in the cases of GeoEye-1 2013 and WorldView-2 DigitalGlobe, 2013.

The aim of this study is to evaluate performances of high-resolution WorldView-2 satellite imagery in basic applications for monitoring of territorial and environmental resources in Phlegrean Area, an emblematic example of mixture of natural and artificial features. For consequence the attention is focalized on the positional and thematic accuracies that can be achieved with those data in reference to identification and mapping of fundamental components such as sea, soil and vegetation.

\section{MATERIALS AND METHODS}

\subsection{Site and Features}

Located west of the city of Naples, Phlegrean area, Fig. 1, was affected by two eruptions that produced widespread ash-flow deposits: The 'Campanian Ignimbrite' (CI) at about 34,000 a bp and the smaller 'Neapolitan Yellow Tuff' (NYT) about 12,000 years ago. This area is surrounded by three other quaternary volcanic centers: Ischia Island, Procida Island and Vesuvius.

Several theories have been postulated since the XVIII century to explain the origins of the eruption products in the area. Breislak (1798) and Scacchi (1890) considered $\mathrm{CI}$ as the result of mud eruptions from centers distributed across the Campanian plain. De Lorenzo (1904) identified three periods: in the first included the CI, in the second the NYT, in the third the products of recent activity. Zambonini (1919) theorized that CI was originated by ash-flow depositions.

Rittmann (1950) hypothesized that a central volcano named Archiflegreo was demolished by the eruption of the CI and the following collapse of the area originated the Phlegrean caldera. In the opinion of Lirer et al. (1987), this caldera was mainly originated after another ample eruption which formed the Neapolitan Yellow Tuff. Scandone et al. (1991) suggest that the Campanian Ignimbrite was provided through a NE-SW fracture neighboring Acerra depression and Posillipo Hill. These authors agreed Lirer et al. (1987) theory on the origin of caldera after the NYT eruption. 


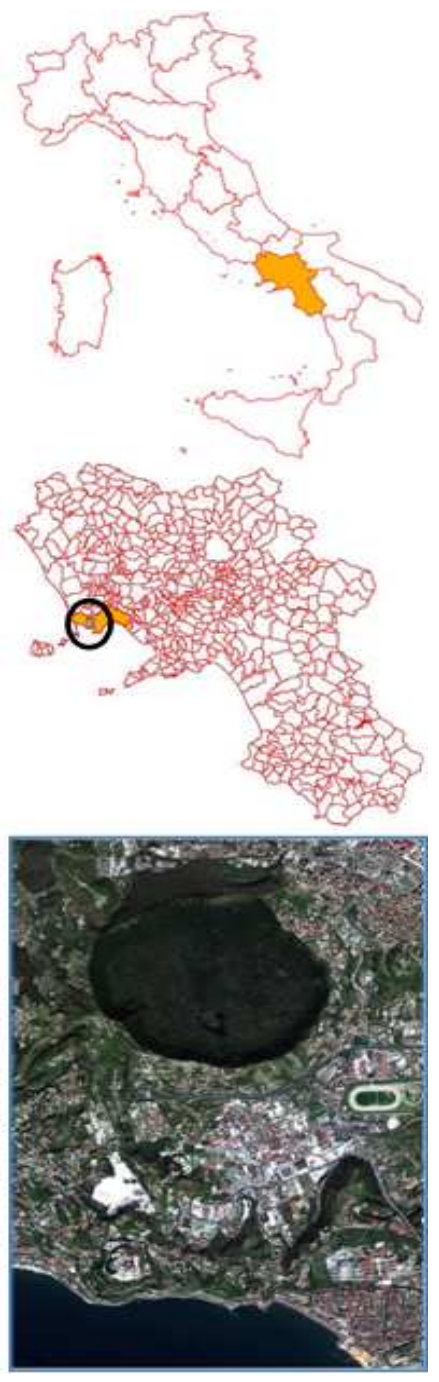

Fig. 1. Study area

Within this area there are sites of special interest such as the Solfatara and Astroni caldera. The Solfatara is famous for its steaming jets of sulphurous vapor at temperatures of $160^{\circ} \mathrm{C}$, the emission of carbonic anhydride and small volcanoes of boiling mud. For these natural characteristics it was considered the mythical entrance to the Ancient Romans' Hell. Sulphur was extracted here in the past and the area was notorious for its mineral waters, natural saunas and mud. The average molar composition of the fluids is approximately $82 \% \mathrm{H}_{2} \mathrm{O}, 17.5 \% \mathrm{CO}_{2}, 13 \% \mathrm{H}_{2} \mathrm{SO}_{4}$ with minor amounts of $\mathrm{H}_{2}, \mathrm{~N}_{2}, \mathrm{CH}_{4}$ and $\mathrm{CO}$.

The Solfatara is the epicentre of the cyclic phenomenon of the rising and lowering of ground level in the Phlegrean Area known as "Bradisismo" by the
Greekbradi $=$ slow, seism $=$ movement. In roman times vertical shifting was already know: the floor of the Serapeo, a roman market built near the sea-shore, was elevated two centuries after its first construction, because of the invasion of the sea water.

At the beginning of XX century levellings showed that the maximum descending was occurring in the city of Pozzuoli and regularly decreased westward and eastward along the coast. This slow sinking of the ground continued until 1968; in the periods 1970-1972 and 1982-1984 two important events of increase occurred in the area (Berrino et al., 1984).

At the point of maximum deformation (located in Pozzuoli), risings of 170 and $182 \mathrm{~cm}$, respectively in the first and in the second above mentioned periods, were measured in reference to the previous levelling. The increase geometry has a circular symmetry around Pozzuoli and regularly declines toward the boundary of the caldera, so it appears as the mirror image of the slow falling observed until 1968.

After the inflation which happened in 1970-72, a partial recovery of some $20 \mathrm{~cm}$ occurred while a decrease of about $70 \mathrm{~cm}$ followed since the end of 1984 . The bell-shaped form of the deformation remained substantially the same during 1982-1984: In spite of considerable vertical variations, horizontal expanse did not undergo a significant change. Explanation of the constancy of the areal extent of the deformation is supplied by Scandone et al. (1991) for which planimetric invariability is due to the caldera structure that is like a barrier. The deflation episodes are connected with the compaction of the loose pyroclastics of the caldera floor while the inflation ones are originated by pressure intensification from lower strata to up.

In Phlegrean area is located the park Cratere of Astroni, a natural reserve, protected by the World Wildlife Fund (WWF) and situated on the western bound of the city of Naples between the ancient road Campana and the plain of Agnano. The Reserve covers a surface of 247 hectares and includes the whole volcanic structure which bears an ever-green Mediterranean oak (Quercus ilex L.) forest in the upper internal edge (Cotrufo et al., 1995).

\subsection{WorldView-2 Satellite Imagery}

WorldView-2 satellite, Fig. 2, has a sun-synchronous orbit at $770 \mathrm{~km}$ with inclination of $97.2^{\circ}$ and was launched on October 8, 2009 from Vandenberg Air Force Base in California. WorldView-2 has a revisit time of 1.1 days at $1 \mathrm{~m}$ Ground Sample Distance (GSD) or less and of 3.7 days at $20^{\circ}$ off-nadir or less $(0.52 \mathrm{~m}$ GSD). Principal characteristics of this satellite are reported in Table 1. 


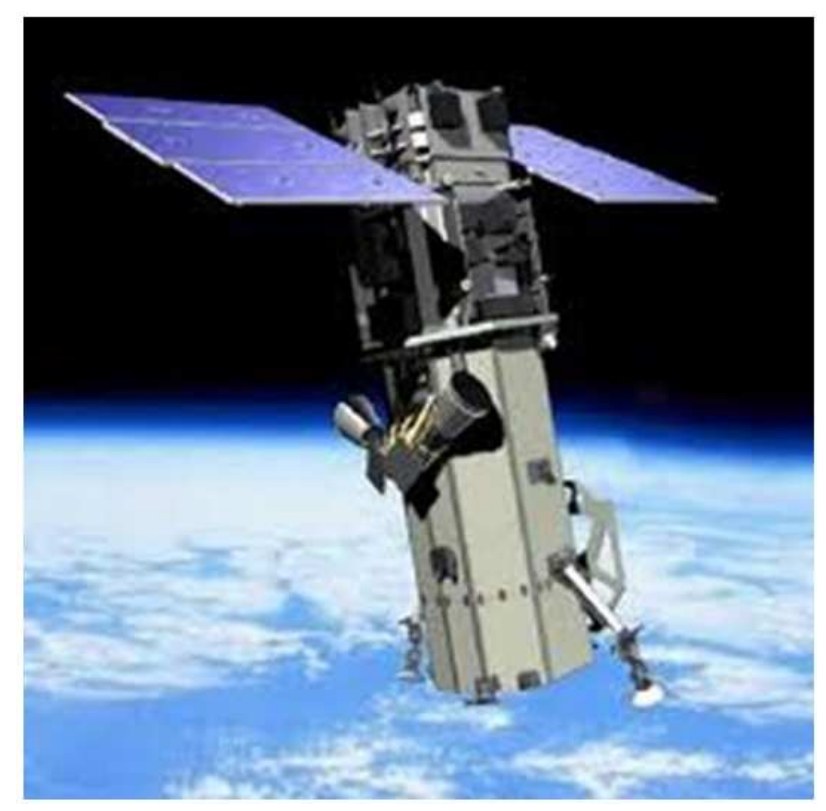

Fig. 2. WorldView-2 satellite

Table 1. Datasheet WorldView-2 satellite

\begin{tabular}{ll}
\hline Launch date & 8 October 2009 \\
\hline Orbitaltitude & $770 \mathrm{~km}$ \\
Orbittype & Sun-synchronous \\
& $(10: 30$ am-descending orbit) \\
Inclinationorbit & $97.2^{\circ}$ \\
Orbitalperiod & $100 \mathrm{~min}$ \\
Swath (nadir) & $16.4 \mathrm{~km}$ \\
Acquisition mode & Synchronous \\
Revisitationperiod & 1.1 days (GSD 1 m) \\
Revisitationperiod (nadir) & 14 days \\
\hline
\end{tabular}

On board of satellite WorldView-2 are present two type of sensors (both with a swath width of $16.4 \mathrm{~km}$ at nadir) that respectively supply multispectral images (Blue: 0.450-0.510 $\mu \mathrm{m}$; Green: 0.510-0.580 $\mu \mathrm{m}$; Yellow 0.585$0.625 \mu \mathrm{m}$, Red: 0.630-0.690 $\mu \mathrm{m}$; Red-Edge 0.705-0.745 $\mu \mathrm{m}$; NIR1 $0.770-0.895 \mu \mathrm{m}$, NIR2 $860-940 \mu \mathrm{m})$ with pixel dimensions $1.84 \times 1.84 \mathrm{~m}$ at nadir and panchromatic images (0.450-0.800 $\mu \mathrm{m}) 0.46 \times 0.46 \mathrm{~m}$ at nadir.

The first type offers a spectral resolution better than the second; the second offers a spatial resolution better than the first. Radiometric resolution for both is 11 bit $(\mathrm{BV}=0-2047)$. WorldView-2 images are distributed with resolution of $0.50 \mathrm{~m}$ (pan) and $2.0 \mathrm{~m}$ (multispectral) DigitalGlobe, 2013.

WorldView-2 images present greater potentialities because of their higher geometric resolutions and number of bands.

\subsection{Geometric Correction of WorldView-2 Satellite Imagery}

For this application WorldView-2 imagery concerning Phlegrean Area acquired on 26 June 2011 was used. Dataset was supplied by the vendors as "orto ready standard product": as indicated by DigitalGlobe, 2013 , it was projectedto a plane using a map projection Universal Transverse of Mercator (UTM) and datum (WGS84), projected to a constant base elevation (calculated on the average terrain elevationestablished for area of interest).In other terms, the dataset is not ortho-rectified in the photogrammetric sense, so geolocation errors are present. Using 30 Check Points (CPs), planimetric differences between rigorous cartographic and effective coordinates present RMS of about 15 m, Table 2. To correct geometric distortions of WorldView-2 satellite imagery Rational Polynomial Functions (RPFs) were used. Relationship between images coordinates $\left(\mathrm{X}^{\prime}, \mathrm{Y}^{\prime}\right)$ and $3 \mathrm{~d}$ object coordinates $(\mathrm{X}, \mathrm{Y}, \mathrm{Z})$ is defined by (Toutin, 2004):

$X^{\prime}=\frac{P_{1}^{n}(X, Y, Z)}{P_{2}^{n}(X, Y, Z)}$

$\mathrm{Y}^{\prime}=\frac{\mathrm{P}_{3}^{\mathrm{n}}(\mathrm{X}, \mathrm{Y}, \mathrm{Z})}{\mathrm{P}_{4}^{\mathrm{n}}(\mathrm{X}, \mathrm{Y}, \mathrm{Z})}$

The generic polynomial $\mathrm{P}_{\mathrm{i}}^{\mathrm{n}}$ is expressed by:

$P_{i}^{n}(X, Y, Z)=\sum_{j-0}^{m_{1}} \sum_{k=0}^{m_{2}} \sum_{I=0}^{m_{3}} a_{j k l} X^{j} Y^{k} Z^{I}$

where, the following relations must be respected:

$$
\begin{aligned}
& 0 \leq \mathrm{m}_{1} \leq \mathrm{n} \\
& 0 \leq \mathrm{m}_{2} \leq \mathrm{n} \\
& 0 \leq \mathrm{m}_{3} \leq \mathrm{n} \\
& \mathrm{m}_{1}+\mathrm{m}_{2}+\mathrm{m}_{3} \leq \mathrm{n}
\end{aligned}
$$

To determine values ofthe polynomial coefficients in Equation 1-3 Ground Control Points (GCPs) which are identifiable in the image must be selected accurately on the map to detect their coordinates. In the case $n=3,78$ coefficients are present in Equation 1 and 2, so at least 39 GCPs must be considered. Usually a greater number of GCPs is used, so to optimize transformation reducing positional errors in the selected points. Accuracy is estimated by the errors in the GCPs as well as in the CPs. Accuracy of solutions depends on the number and the distribution of GCPs. 
Pasquale Maglione et al. / American Journal of Geosciences 3 (1): 1-12, 2013

Table 2. Statistic parameters of planimetric differences between rigorous cartographic and effective coordinates for $30 \mathrm{CPs}$

\begin{tabular}{llllll}
\hline $30 \mathrm{CPs}$ & RMS xy $(\mathrm{m})$ & $\Delta \mathrm{xy}$ medium $(\mathrm{m})$ & $\Delta \mathrm{xy} \min (\mathrm{m})$ & $\Delta \mathrm{xy} \max (\mathrm{m})$ & $\sigma_{\mathrm{xy}}(\mathrm{m})$ \\
\hline Preliminary test & 15.798 & 15.772 & 11.466 & 17.668 & 0.911 \\
\hline \begin{tabular}{l} 
Table 3. Statistic parameters of residuals (meters) obtained for the GCPs using RPFs \\
\hline $80 \mathrm{GCPs}$
\end{tabular} & RMS xy $(\mathrm{m})$ & $\Delta \mathrm{xy}$ medium $(\mathrm{m})$ & $\Delta \mathrm{xy} \min (\mathrm{m})$ & $\Delta \mathrm{xy} \max (\mathrm{m})$ & $\sigma_{\mathrm{xy}}(\mathrm{m})$ \\
\hline $\begin{array}{l}\text { Rational polynomial } \\
\text { function }\end{array}$ & 0.886 & 0.804 & 0.054 & 1.923 & 0.476 \\
\hline
\end{tabular}

Table 4. Statistic parameters of residuals (meters) obtained for the CPs using RPFs

\begin{tabular}{llllll}
\hline 15 CPs & RMS xy $(\mathrm{m})$ & $\Delta x y$ medium $(\mathrm{m})$ & $\Delta x y \min (\mathrm{m})$ & $\Delta \mathrm{xy} \max (\mathrm{m})$ & $\sigma_{\mathrm{xy}}(\mathrm{m})$ \\
\hline $\begin{array}{l}\text { Rational polynomial } \\
\text { function }\end{array}$ & 1.118 & 0.955 & 0.120 & 1.958 & 0.582 \\
\hline
\end{tabular}

Best results, in fact, are obtained using a large number of GCPs that must be regularly distributed in reference both to planimetryand altimetry. Using OrthoEngine (PCI Geomatica v. 2012) software, RPFs were applied with $80 \mathrm{GCPs}$ and $15 \mathrm{CPs}$, which coordinates in UTM-WGS84 were derived from official regional ortophotos (scale: 1:2,000).

As indicated in Table 3 and 4, residuals are comparable with pixel dimensions, so the corrected image can be used at least at scale 1:5,000.

\subsection{DTM}

Digital Terrain Model (DTM) of the area was necessary both to correct geometric distortions of the imagery (if not available,application of the Equation 1 and 2 is impossible) and to build $3 \mathrm{~d}$ thematic models.

To create DTM, maps in vector form, scale 1:5,000, georeferred in UTM-WGS 84 datum, were considered, Fig. 3.

Using ArcMap(ArcGIS 10.1) software, queries on the maps were applied to extract elevation data (points and polylines), Fig. 4. With 3D Analyst, extension of the same software ArcGIS, TIN (Triangulated Irregular Network) was built, Fig. 5. This model type is a vector-based representation of the physical land surface (or sea bottom), done by irregularly distributed nodes with threedimensional coordinates ( $x, y$ and $z$ ) that are connected by lines to form a network of non-overlapping triangles.

TIN appears to have been independently invented in North America at least within three different research activities in the early 1970s: one was by Thomas K. Peuker, a cartographer in an academic geography department; one was by engineers working at Engineering-Science, a consulting firm based in northern Virginia; and one was by Christopher Gold, a geologist in academia, for representing underground geological surfaces (Mark, 1997). Points and line vertices contained in the input data sources become the nodes that are incorporated in the TIN triangulation, Fig. 6. Each of them maintains the original z-value and it is joined with its nearest neighbors by edges to form triangles in the respect of Delaunay criterion (name derived by Russian mathematician Boris Nikolaevich Delaunay): circle circumscribing every triangle contains no points from the dataset in its interior (Lo, 2013). A node may have two or more edges, while each edge has two nodes. Along the edge from one node to the other it is possible to calculate slope.

Because the $\mathrm{x}, \mathrm{y}$ and $\mathrm{z}$ coordinate values of a triangle's three nodes are known, information about the facet, such as slope and surface area, can be derived. If the entire set of triangles is considered as a whole, additional information about the surface, including volume and visibility analysis, can be obtained.

The topological structure of a TIN is defined by recording the following data: the triangle number, the numbers of each adjacent triangle, the three nodes defining the triangle, the $\mathrm{x}, \mathrm{y}, \mathrm{z}$ coordinates of each node, the type of each triangle edge (hard or soft).

In this study TIN include 681,075 nodes and $1,362,113$ triangles. $Z$ range is $0-461 \mathrm{~m}$. Using $3 \mathrm{~d}$ Analyst, TIN was transformed in grid with cell dimensions $2 \times 2 \mathrm{~m}$, Fig. 7-9.

\subsection{NDVI}

Normalized Difference Vegetation Index (NDVI) necessitates red and infrared remotely sensed images to evaluate whether the target being observed contains live green vegetation or not. In fact it is a good measure of the physiological activity of plants. NDVI is based on the low level of reflectance due to the photosynthesis: chlorophyll that is present in leaves absorbs solar radiation in the Visible Spectral Region (VIS) for vital functions of the plants. On the other hand solar radiation in the Near-Infrared spectral band (NIR) is reflected by leaves cells because the energy level per photon in that domain is not adequate to synthesize organic molecules. 
Pasquale Maglione et al. / American Journal of Geosciences 3 (1): 1-12, 2013

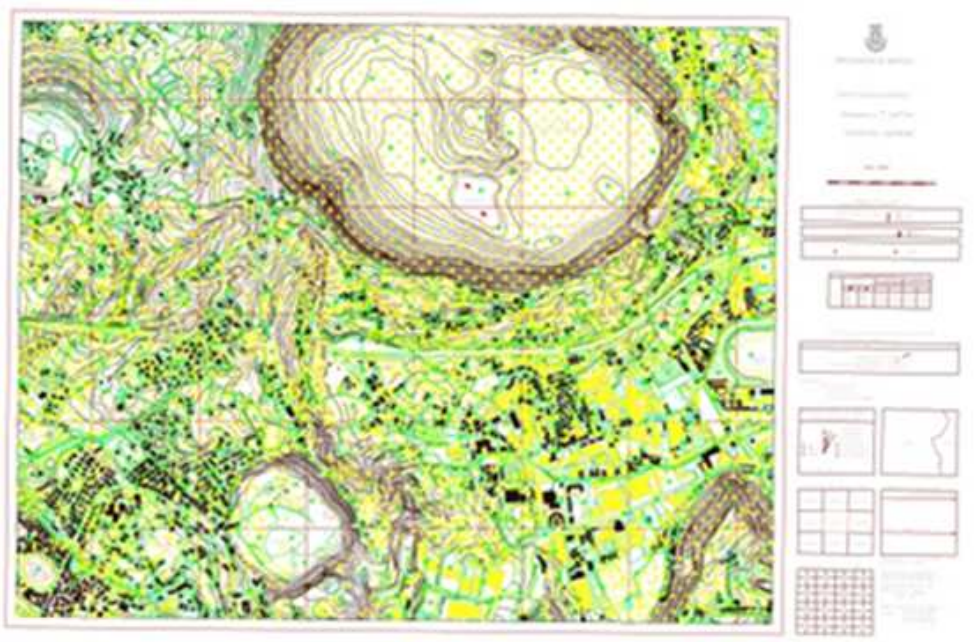

Fig. 3. One of Vector maps used for orto-rectification process

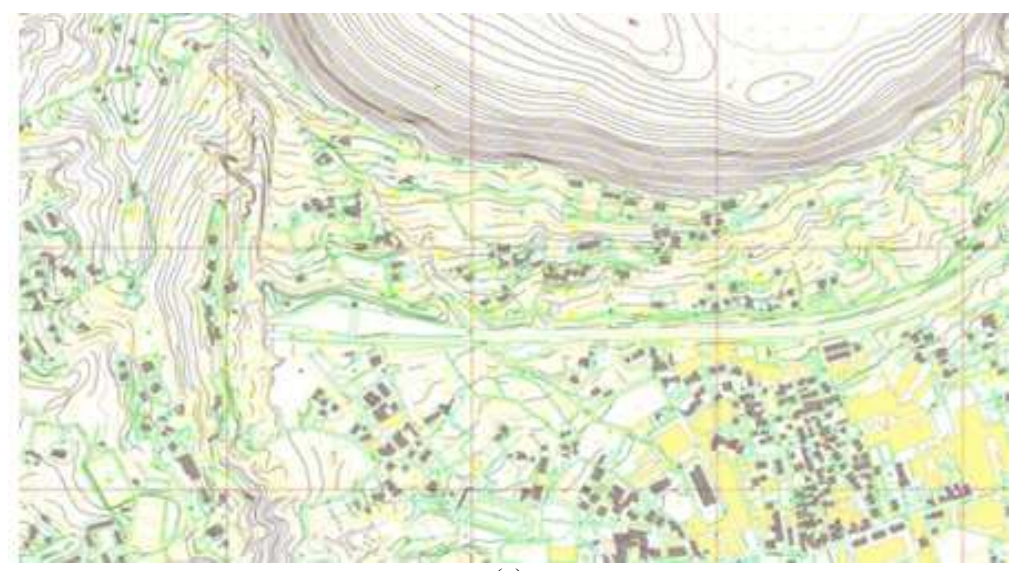

(a)

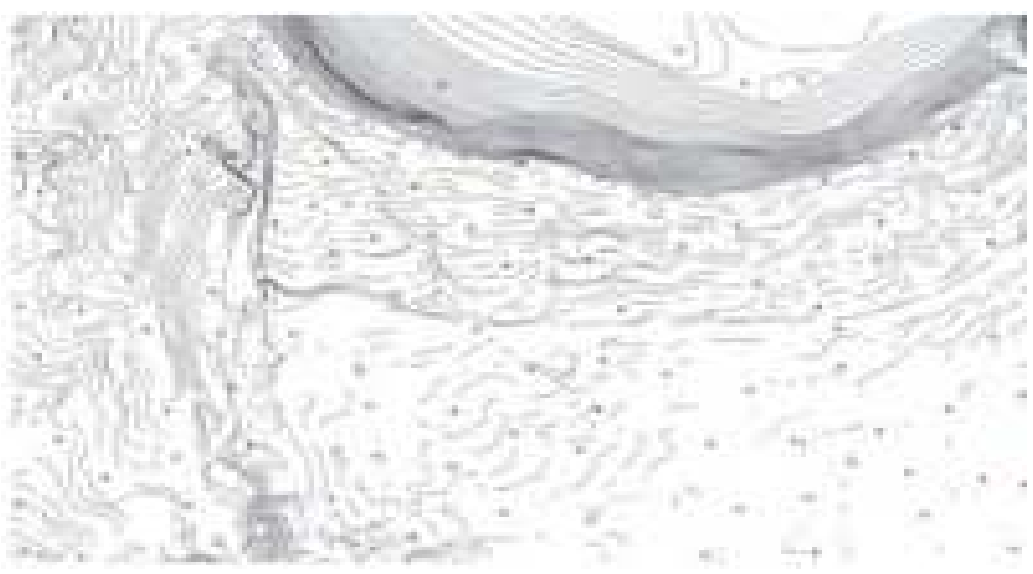

(b)

Fig. 4. (a) Particular of vector map; (b) results of query for elevation data extraction: points and polylines 
Pasquale Maglione et al. / American Journal of Geosciences 3 (1): 1-12, 2013

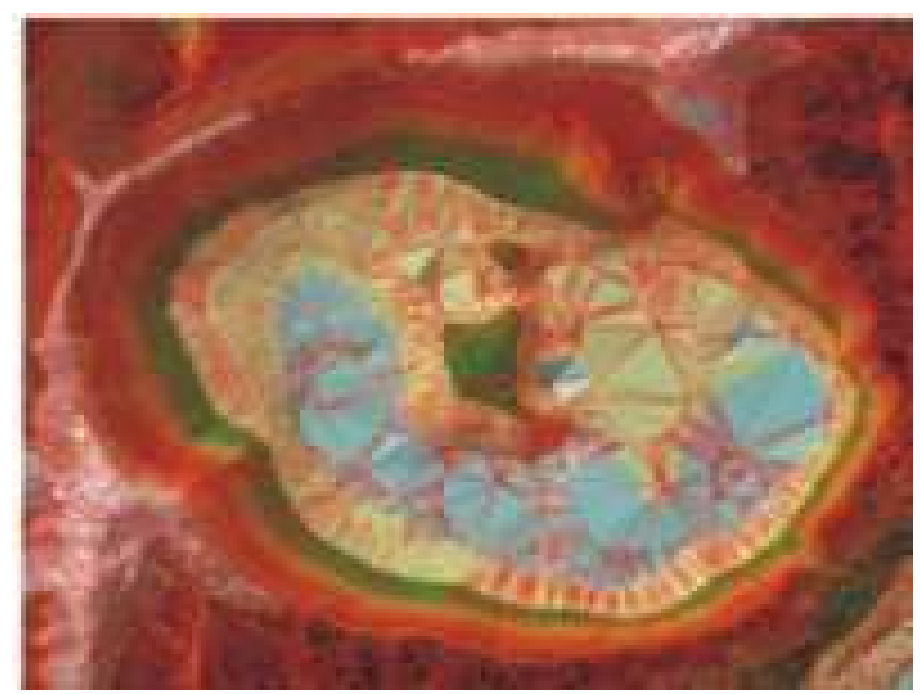

Fig. 5. Particular of TIN: Astroni Caldera

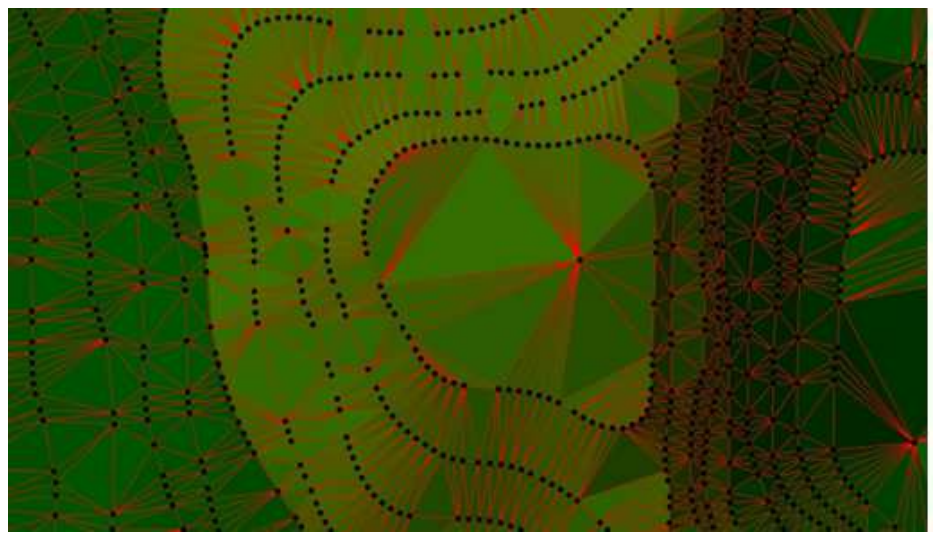

(a)

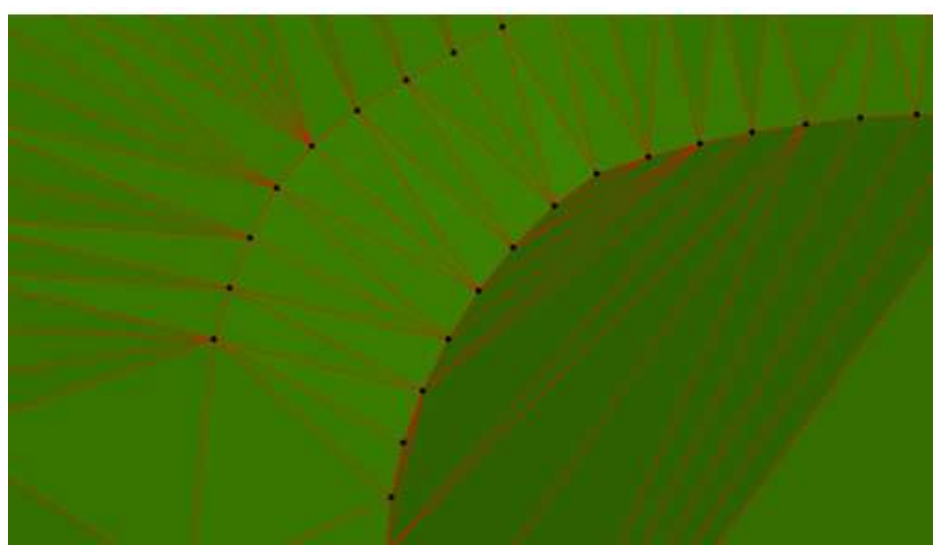

(b)

Fig. 6. Two particulars of TIN (edges and nodes) at different scale 
Pasquale Maglione et al. / American Journal of Geosciences 3 (1): 1-12, 2013

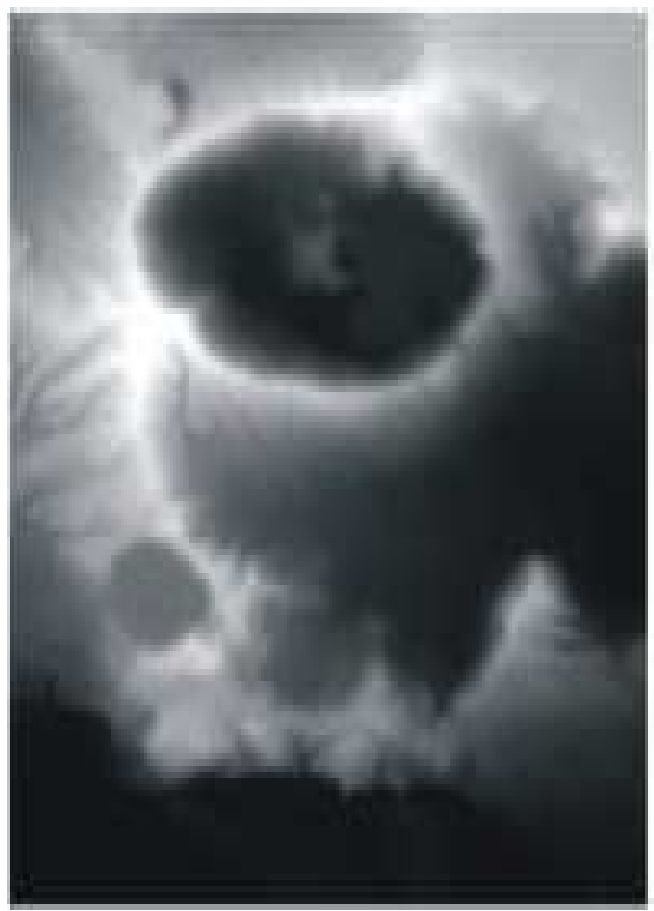

Fig. 7. DTM: top view

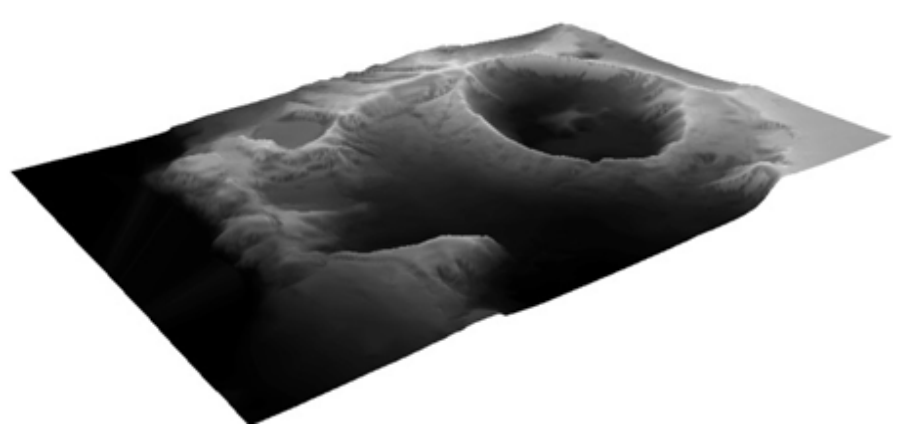

Fig. 8. DTM: 3d view

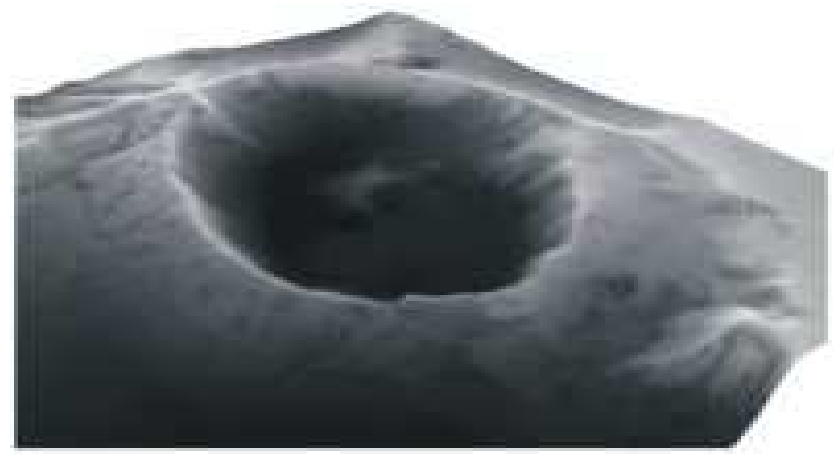

Fig. 9. DTM: particular of 3d view (Astroni Caldera) 


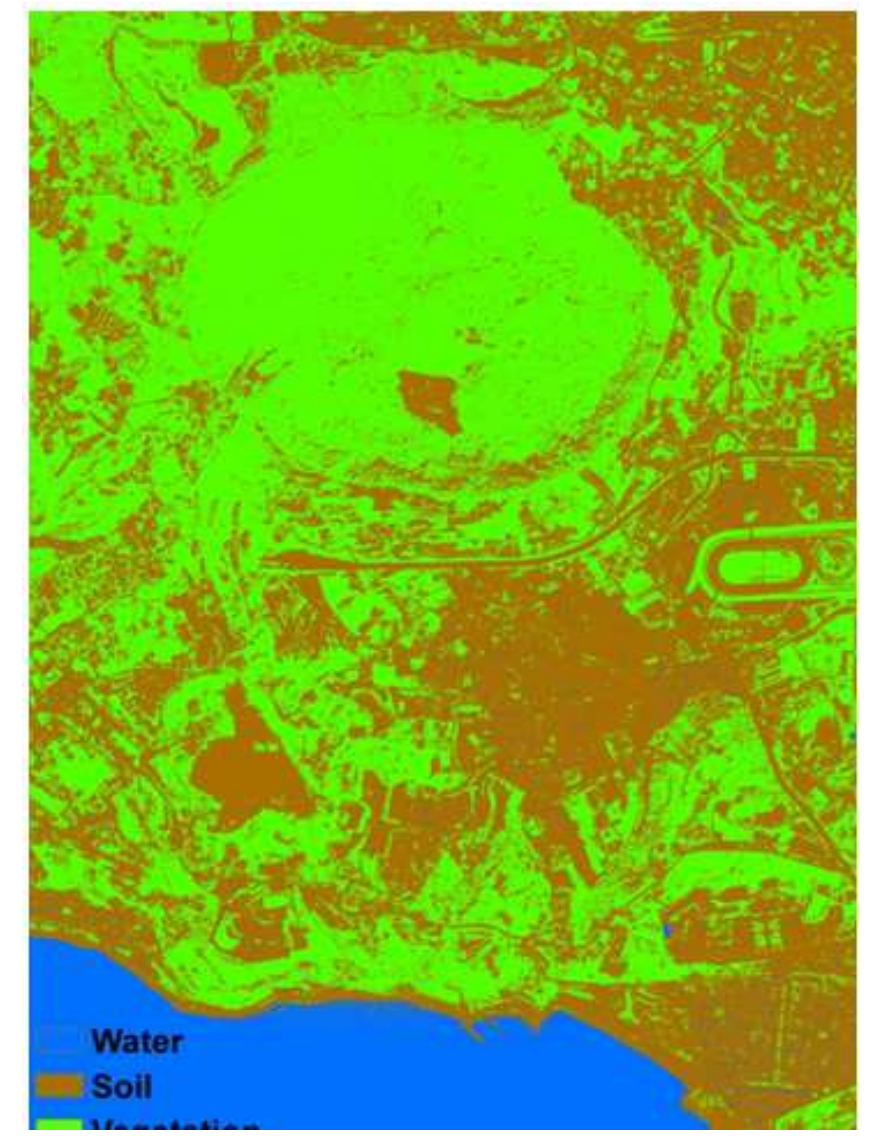

Fig. 10. NDVI

For this reasons live green plants are relatively dark in the VIS and relatively bright in the NIR.

The NDVI formula is the following Equation 4:

$$
\mathrm{NDVI}=\frac{\mathrm{NIR}-\mathrm{Red}}{\mathrm{NIR}+\mathrm{Red}}
$$

Where:

NIR = The spectral reflectance measured in the nearinfrared region

RED $=$ The spectral reflectance measured in the red region

NDVI values can range from -1.0 to 1.0 , but common values for green vegetation during the growth season are between 0.2 and 0.8 (Guastaferro et al., 2012).

Calibration, noise and mutable irradiance values caused by changing atmospheric conditions, sun angles, topography, clouds and shadows produce signal variations: NDVI is a ratio, so it cancels out a large proportion of these effects improving the results of the classification. Oceans, seas, lakes, rivers, in other terms all features that are constituted by water, present a rather low reflectance in Red as well as in NIR spectral band: for consequence their presences produce negative or very low positive NDVI values. Also clouds and snowfields are characterized by negative values of this index. Soils usually present spectral reflectance in NIR somewhat larger than the red, so for them NDVI values are small positive (say 0.1 to 0.2 ). Availability of sufficient ground data permits to use NDVI for calculation and prediction of various territorial characteristics, such as primary production or dominant species. In this study NDVI was applied to Red and NIR2 bands of WorldView 2, Fig. 10. To establish thresholds of separation among soil, vegetation and water, Table 5, Maximum Likelihood (ML) method was used. 


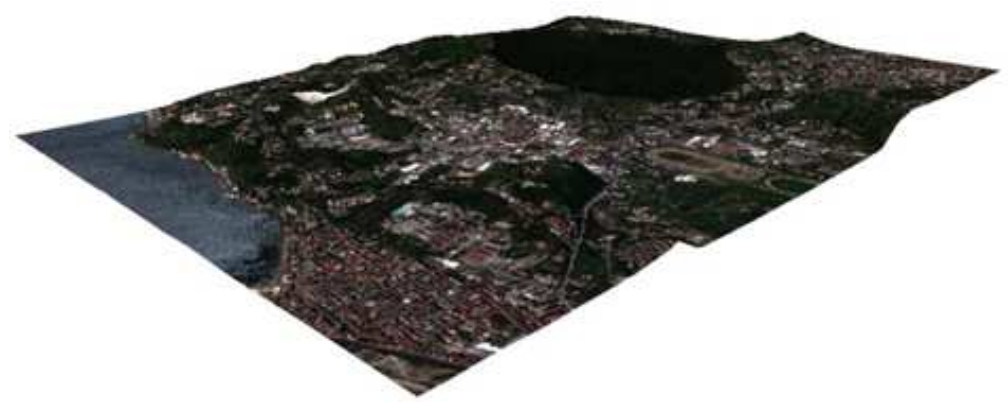

Fig. 11. 3d photorealistic model: overview

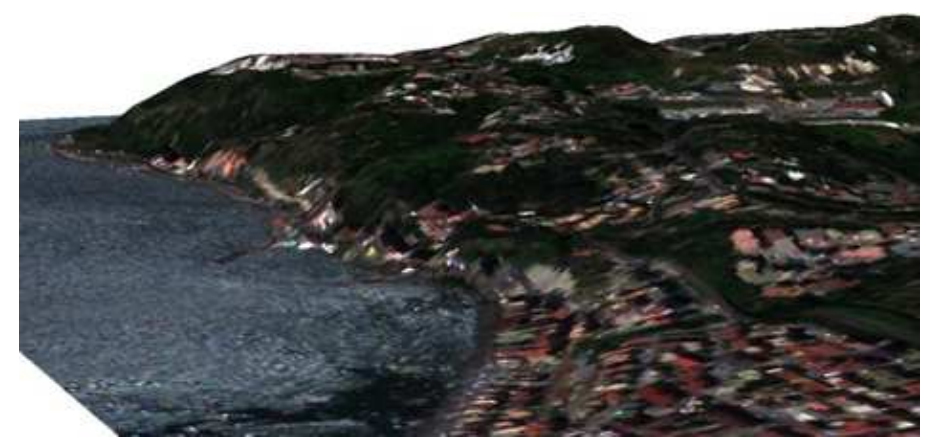

Fig. 12. Particular of $3 \mathrm{~d}$ photorealistic model: coastal zone

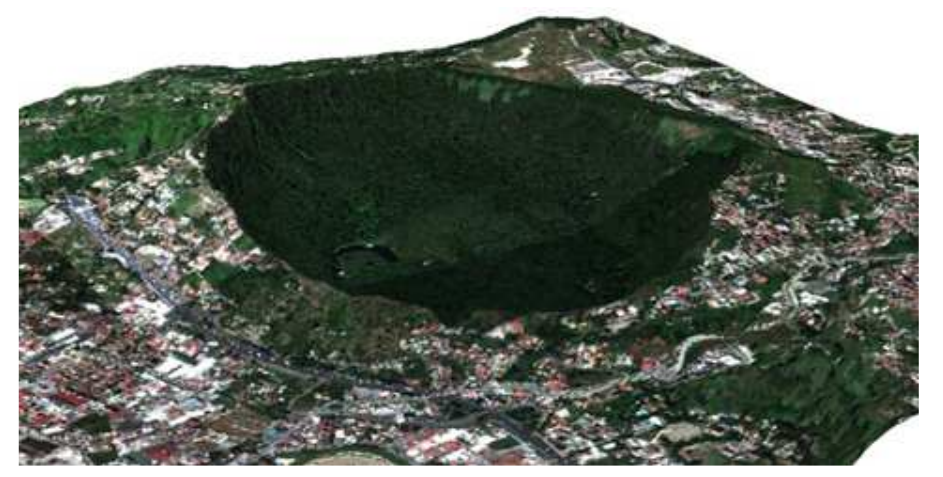

Fig. 13. Particular of $3 \mathrm{~d}$ photorealistic model: Astroni Caldera

To establish quality of classification results, indexes (producer, user, overall accuracy and Cohen Index; Foody, 2011) were calculated: Values for training and test sites are reported in Table 6-8.

\subsection{3d Photorealistic Model}

Photorealistic models facilitate exploration phase of geo-studies: if survey is fundamental for data acquisition and phenomena monitoring, availability of detailed virtual reproductions can support activities plan. Those models are obtained using ortho-images that are typically derived by air-photos: high resolution sensors on satellite can supply adequate data, such as in the case of WorldView-2. In this study $3 \mathrm{~d}$ photorealistic model was achieved using RGB composition with the correspondent bands of the orthorectified dataset as well as the above described DTM. However in most applications the resolution of DTM is considerably less than that of the image: A typical ratio between resolutions is 1:5 (Cohen and Gotsman, 1994). 
Table 5. Thresholds for NDVI

\begin{tabular}{lcc}
\hline NDVI & Water-soil & Soil-vegetation \\
\hline Threshold & -0.139 & 0.353 \\
\hline
\end{tabular}

Table 6. Producer and user accuracies for training sites

\begin{tabular}{lllc}
\hline Training & Water & Soil & Vegetation \\
\hline Producer accuracy & 0.97 & 0.97 & 0.99 \\
User accuracy & 0.98 & 0.96 & 0.99 \\
\hline
\end{tabular}

Table 7. Producer and user accuracies for test sites

\begin{tabular}{lllc}
\hline Test & Water & Soil & Vegetation \\
\hline Producer accuracy & 0.97 & 0.93 & 0.92 \\
User accuracy & 0.92 & 0.91 & 0.96 \\
\hline
\end{tabular}

Table 8. Overall accuracy and Cohen Index for training and test sites

\begin{tabular}{llr}
\hline & Overall accuracy & Cohen index \\
\hline Training & 0.98 & 0.97 \\
Test & 0.93 & 0.89 \\
\hline
\end{tabular}

To increase quality level of the photorealistic model, in this study DTM presents the same cells size of true color RGB composition $(2 \times 2 \mathrm{~m})$ : its visualizations at different points of view are reported in Fig. 11-13.

\section{DISCUSSION}

Using raster maps (ortho-photos) in scale 1:2,000 for planimetric coordinates of GCPs and vector maps in scale 1:5,000 for elevation of GCPs as well as for DTM construction, the results of geometric correction of WorldView-2 present satisfactory levels of accuracy. In fact planimetric residuals on GCPs as well as on CPs remark that the resulting images can be used with nominal scale at least 1:5,000 for pan and, in consideration of pixel dimensions, 1:10,000 for multispectral images.

NDVI application in combination with Maximum Likelihood method for thresholds determination permitted to identify vegetation area with very high accuracy.

Adoption of DTM with the same resolution of RGB composition supplied high quality photorealistic model comparable with those usually derived by air-photos.

\section{CONCLUSION}

Because of their high level of spatial and spectral information WorldView-2 images can strongly support studies and applications of geosciences. For a significant area such as Phlegrean region they constitute precious fonts of information to achieve with regular time lag for continuous monitoring actions. Every 14 days nadir imagery can be acquired, but, if it is necessary, for example in the case of emergency situations, revisit time can be reduced (about 1.1 day even if with $1 \mathrm{~m} \mathrm{GSD}$ ). Availability of eight bands within VIS and NIR spectral region facilitates operations of classification to distinguish use/land cover. NDVI can be applied using Red and NIR 2 bands and its classification to distinguish vegetated areas is facilitated with the ML application. High quality photorealistic models can be generated using VIS bands in RGB compositions and DTM with the same cell size $(2 \times 2 \mathrm{~m})$.

\section{ACKNOWLEDGEMENT}

This study describes results of research activities within the project PRIN 2008 financed by MIUR (Ministero dell'Istruzione, dell'Università e della Ricerca Scientifica) -Italy and developed at University of Naples "Parthenope". We would like to thank Prof. Raffaele Santamaria, coordinator of this project, for scientific support to our activities.

\section{REFERENCES}

Aguilar, M.A., M.M. Saldana and F.J. Aguilar, 2013. GeoEye-1 and WorldView-2 pan-sharpened imagery for object-based classification in urban environments. Int. J. Remote Sens., 34: 2583-2606. DOI: $10.1080 / 01431161.2012 .747018$

Basile, G.M., P. Maglione, C. Parente and R. Santamaria, 2011. Cartography and remote sensing for coastal erosion analysis. Proceedings of the International Conference on Coastal Processes, Apr. 27-29, IEEE Xplore Press, WIT Press, UK., pp: 65-76. DOI: 10.2495/CP110061

Berrino, G., G. Corrado, G. Luongo and B. Toro, 1984. Ground deformation and gravity changes accompanying the 1982 Pozzuoli uplift. Bull. Volcanol., 47: 187-200. DOI: 10.1007/BF01961548

Breislak, S., 1798. Topografia Fisica Della Campania. 1st Edn., Kessinger Publishing, ISBN-10: 1120091004, pp: 384.

Campbell, J.B. and R.H. Wynne, 2011. Introduction to Remote Sensing. 3rd Edn., Guidolf Press, New York, ISBN-10: 1572306408, pp: 621.

Cohen, D. and C. Gotsman, 1994. Photorealistic terrain imaging and flight simulation. Comput. Graphics Applic., 145: 10-12. DOI: 10.1109/38.267465 
Cotrufo, M.F., A.V. De Santo, A. Alfani, G. Bartoli and A. De Cristofaro, 1995. Effects of urban heavy metal pollution on organic matter decomposition in Quercus ilex L. Woods. Environ. Pollut., 89: 81-87. DOI: 10.1016/0269-7491(94)00041-B

De Lorenzo, G., 1904. L'Attività vulcanica dei campi flegrei. Rend. Acc. Scienze Fisiche e Matematiche Serie, 3: 203-221.

Foody, M.G., 2011. Classification accuracy assessment. IEEE Geoscience and Remote Sensing Society Newsletter, Cumulative, 159: 8-14.

Gibson, P., 2000. Remote Sensing Principles and Concepts. 1st Edn., Routledge, London, ISBN-10: 0415196469, pp: 184.

Guastaferro, F., C. Oliviero, C. Parente and R. Santamaria, 2012. Improving geometric resolution of NDVI results with panchromatic and multispectral data fusion. Proceedings of the IEEE GOLD Conference, Jun. 4-5, GianniniEditore, Italy, pp: 76-78.

Huete, A.R., 1988. A Soil-Adjusted Vegetation Index (SAVI). Remote Sens. Environ., 25: 295-309. DOI: 10.1016/0034-4257(88)90106-X

Kauth, R.J. and G.S. Thomas, 1976. The Tasselled CapA Graphic Description of the Spectral-Temporal Development of Agricultural Crops as Seen by LANDSAT. Purdue University Purdue e-Pubs.

Lauer, D.T., S.A. Morain and V.V. Salomonson, 1997. The landsat program: Its origins, evolution and impacts. Photogrammetric Eng. Remote Sens., 63: 831-838.

Lein, J.K., 2012. Environmental Sensing: Analytical Techniques for Earth Observation. 1st Edn., Springer, New York, ISBN-10: 1461401437, pp: 338.

Lirer, L., G. Luongo and R. Scandone, 1987. On the volcanological evolution of Campi Flegrei. EOS Trans. Am. Geophysical Union, 68: 226-234. DOI: 10.1029/EO068i016p00226
Lo, S.H., 2013. Delaunay triangulation of non-uniform point distributions by means of multi-grid insertion. Finite Elements Anal. Design, 63: 8-22. DOI: 10.1016/j.finel.2012.08.005

Mark, D.M., 1997. The history of geographic information systems: Invention and re-invention of Triangulated Irregular Networks (TINs). Proceedings of the Annual Conference and Exposition GIS/LIS, Oct. 28-30, Ohio, pp: 267-272.

Morain, S.A. and A.M. Budge, 2012. Earth Observing Data for Health Applications. In: Environmental Tracking for Public Health Surveillance, Morain, S.A. and A.M. Budge (Eds.), CRC Press, London, ISBN-10: 041558471X, pp: 3-18.

Rittmann, A., 1950. Sintesi geologica dei Campi Flegrei. Boll. Soc. Geol. Italiana, 69: 117-128.

Rouse, J.W., R.H. Haas, J.A. Schell and D.W. Deering, 1974. Monitoring vegetation systems in the great plains with ERTS. Proceedings of the third ERTS-1 Symposium, Dec. 10-14, NASA, pp: 309-317.

Scacchi, A., 1890. The Volcanic Region of Campania Fluorifera-Lacustrine and Marine Deposits Encountered in Drilling at the Via Appia Antica. Memories to Serve the Description of the Geological Map of Italy. 2nd Edn., Barbera, Florence, pp:131.

Scandone, R., F. Bellucci, L. Lirer and G. Rolandi, 1991. The structure of the campanian plain and the activity of neapolitan volcanoes. J. Volcanol. Geothermal Res., 48: 1-31. DOI: 10.1016/0377-0273(91)90030-4

Simonett, D.S. and F.T. Ulaby, 1983. Manual of remote sensing. Int. Appli., 2: 1232-1232.

Toutin, T., 2004. Geometric processing of remote sensing images: Models, algorithms and methods. Int. J. Remote Sens., 25: 1893-1924. DOI: 10.1080/0143116031000101611

Zambonini, F., 1919. Il tufo pipernoide della campania e i suoi minerali. Tipografia Ditta L. Cecchini, Roma, pp: 130 . 